\title{
Assessment of Yoruba Language Teachers' Utilization of Evaluation Instruments in Grading Students
}

\author{
Abijo J.A, PhD \\ Institute of Education, University of Ibadan
}

doi: 10.19044/esj.2016.v12n31p72 URL:http://dx.doi.org/10.19044/esj.2016.v12n31p72

\begin{abstract}
The study assessed Yoruba language teachers' utilization of evaluation instruments in grading students.Using multistage sampling procedure, one hundred Yoruba language teachers who teach senior secondary classes two and three were randomly selected from 75 schools in three states of Nigeria (Oyo, Osun and Ekiti). Data were analysed using descriptive (frequency count and percentages) and t-test statistics. Result indicates that Yoruba language teachers adopt the multiple choice test and a combination of essay and objective tests in that order to grade students. Other evaluation instruments used and listed in order of utilization are oral test, practical work, submitted homework and student's notes. Evaluation instrument that encourage higher thinking such as practical work and submitted home work are never or less often used respectively. In terms of group differences in the utilization of these instruments, findings show that the utilization of the multiple choice test is sensitive to teacher experience and professional status. This implies that teachers with more experiences (6 years and above) and those with professional training use multiple choice tests more frequently. Also, there is no statistical significant difference between male and female utilization of evaluation instruments. It was thus recommended that Yoruba language teachers should be exposed to training and re-training programme on the importance of using practical class activities and using of submitted home work for students as an evaluation instrument in grading Yoruba language students in schools
\end{abstract}

Keywords: Assessment of Yoruba Language Teachers, Utilization of Evaluation Instruments, Evaluation Instruments, Grading of students

\section{Introduction}

Educational assessment is the process of documenting, in usually measurable terms, knowledge, skills, attitudes and belief. It is the process of establishing the status of performance of an individual or group in a given 
task usually with reference to the expected outcomes. It is concerned with qualitative and quantitative description of objects or events. Assessment is not based on the achievement scores of the learner's only, but also their behavior, personalities, attitudes etc. in a learning environment. It is generally used to refer to what students learnt and gauge student's progress since at every level of education, student are subjected to one examination.

Evaluation of teaching involves the gathering of valid data on attainment of educational objectives, analysis and fashioning information to and judgment on effectiveness of an educational programme. A successful evaluation should generate outcomes that are valid and reliable and also indicating directions for improvements. Students learning can be facilitated through evaluation process in various ways namely; the evaluation instruments can clarify instructional objectives for both the teacher and students, the evaluation instruments can provide the studies with operational definition of how the objective of instrument are to be achieved and lastly a good teacher should use evaluation systematically to assess various phase of instruction and learner's performance because outcomes of learning are sometimes used for taking high-stake decision on learner's progress, therefore the measure obtain should be with right instruments IsiugoAbanihe (2006) The evaluation instruments used in collecting the data to make the judgment of whether learners should proceed or retained must be valid and reliable.

The main function of educational evaluation in teaching is the improvement of students learning. In view of this, there is need for proper planning and identification of all important behavioral objectives of instruction which should be clearly defined, specific and measurable terms and should be evaluation related, Ajala (2005) supporting the views above by discussing the relationship between instruction and evaluation assets that good teaching is impossible without plan evaluation since the quality of instruction depends on the quality of evaluation intended. He stressed further that evaluation of specific learning outcomes and assignment of responsibility for learning success and failure are essentials professional competencies. Such an evaluation will not only help assign responsibility for specify learning outcomes but should also result in improvement of learning instructions.

Evaluation in the cognitive domain requires the measurement of different cognitive skills such as knowledge, comprehension, application, synthesis, and analysis (Obemeta,2000; Onibokun,1999). According to Okpala \& Onocha (1994)evaluation is interested in the process used in gathering any information on which judgments is based ,therefore the expectation is that teacher should employ various evaluation instruments to measure outcomes of learning. Different instruments that are simple or 
complex could be used by the teacher to access curricular content depending on the purpose of the assessment or the importance of the decision to be made based on the outcomes of the result Okwilagwe (2011).Though Okpala, Onocha \& Oyedeji (1993) offered a comprehensive list of evaluation instruments covering the cognitive affective and psychomotor domains, the instrument (tools)of interest in this study focus on the evaluation of cognitive and psychomotor domain. These are; essay test, practical work, submitted homework, multiple choice test, combination of multiple choice and essay test and students notes. To achieve effectiveness, each of the instruments must undergo proper construction processes and or properly planned and documented and made available to the teacher and learner so as to enable them monitor the progress of learning. In addition, their proper utilization should ensure that an accurate picture of students' 'total achievement is obtained. In Yoruba language teaching, a variety of formative instrument is available. Data can be collected to evaluate learning that cannot be directly observed, such as reading comprehension. On the other hand, observation instrument can be demonstrated through performance. There are various evaluation instrument used to collect data such as Checklist, Rating scale, Observation chart, and rubrics. The model or methodology used to gather the data should be a specified step-by-step procedure. It should be carefully designed and executed to ensure the data is accurate and valid.

Previous studies tend to suggest that assessment strategies have direct impact on students' learning. The importance of these findings is that the mode of assessment employed by the teacher determines students' learning approaches whether 'surface or deep' learning (Lee, 1994). While the overreliance on traditional pencil-and-paper tests tends to encourage memorization which leads to the employment of surface approaches to learning assessment forms that measure higher-order thinking have been found to be associated with deep-learning approaches. The use of practical work in Yoruba language for instance can be classified as belonging to the class of portfolios used in students' evaluation. The use of practical work do not only enhance learning but could develop better articulation of thoughts, organizational and reporting skills which reduces students over dependence on the teacher for learning and enhances students self-learning. One benefit of measuring higher cognitive domain is that it is possible to asses a variety of outcomes. Also, students' interest and motivation are arrested and sustained when they observe that some assessment tasks are real and natural.

Scholars such as Obemeata (2003) contend that quality teachers determine quality schools and invariably influence students' achievement. Other study like Adepoju(2002) revealed that teachers characteristics such as experience and qualification along with age and location, influence students 
achievement. The poor performance in secondary school Yoruba language has continued to generate concern among education. In trying to find solution to the problem, previous students for instance, Abijo(2009) positing different methods of teaching essay writing in Yoruba language. Despite the numerous method of teaching the language, students' performance has not been good enough. It has become imperative to continue to seek ways to avert the problem of poor student academic performance. As highlighted in this work, research evidence has linked teachers' method of evaluation to the type of learning strategies adopted by students.

In the light of the foregoing, this study sets out to assess Yoruba language teachers' utilization of education instruments with a view to providing insight to the depth of learning that is undertaken by students at the senior secondary school level classrooms in Nigeria.

\section{Research Question}

1. How often do teachers utilize evaluation instrument in grading students in Yoruba language?

2. Is there any significant group difference (based on gender, teaching experience and professional status) in teachers' utilization of the evaluation instruments?

\section{Methodology}

The multi stage sampling procedure was adopted in the study. Three states were randomly selected from the six states in the South-Western Nigeria Yoruba speaking states, from each selected state, five secondary schools were randomly selected and one SS1 and SS2 Yoruba language teacher selected per school to participate in the study. A total of 100 Yoruba language teachers finally constitute the study sample.

\section{Instrumentation}

The scale of Utilization of Evaluation Instrument (SUEI) was adopted from the "How Nigerian Children Learn" study conducted by the Institute of Education, University of Ibadan for the World Bank in 2002. It consisted of various types of Evaluation instruments such as "Use of essay, multiple choice, oral questions and projects. The teachers were asked to report how often they used these instruments during evaluation. The test-retest reliability method using 50 teachers to establish the consistency of their responses yielded a reliability value of 0.85

\section{Analysis}

Descriptive (frequency counts and percentages) and inferential statistics(t-test) were used to analyze the data collected. 


\section{Results:}

Table 1: Extent of utilization of Evaluation Instrument by Yoruba language teachers EVALUATION INSTRUMENT often \% sometimes \%

Never \%

Essay type of question

Multiple choice test

Multiple choice and essay question

Oral test

Practical work

Submitted homework

Students' note

$\begin{array}{ccc}66 & 34 & - \\ 48 & 52 & - \\ 79 & 21 & - \\ 15 & 59 & 26 \\ 02 & 12 & 86 \\ 10 & 15 & 75 \\ 24 & 27 & 49\end{array}$

The result of the Yoruba language teachers' extent of utilization of evaluation instruments is presented in table 1 above. The table shows that the $66 \%, 48 \%$ and $79 \%$ of the Yoruba teachers respectively often used the essay type of question, multiple choice test and multiple choice and essay questions. Oral test is sometimes used by $59 \%$ of the teachers, multiple choice test, by 34\%, of the teachers, Students note by $27 \%$, and Submitted homework by $15 \%$ of the teachers. The table also shows that practical work in Yoruba language and submitted home work are never used by $86 \%$ and $75 \%$ of the teachers.

Table 2a: Teachers utilization of evaluation instruments by teaching experience

\begin{tabular}{|c|c|c|c|c|c|c|c|c|}
\hline EVALUATION & YEARS OF TEACHING & $\mathrm{N}$ & Mean & SD & t-value & df & $\operatorname{sig}$ & mark \\
\hline INSTRUMENT & EXPERIENCE & & & & & & & \\
\hline Essay type of & Below 5 years & 30 & 2.73 & 0.450 & & & & \\
\hline Question & 6 years and above & 70 & 2.63 & 0.487 & 1.008 & 98 & .316 & NS \\
\hline Multiple choice & Below 5 years & 30 & 2.63 & 0.490 & & & & \\
\hline Test & 6 years and above & 70 & 2.41 & 0.496 & 2.030 & 98 & .045 & NS \\
\hline Multiple choice & Below 5 years & 30 & 2.70 & 0.496 & & & & \\
\hline $\begin{array}{l}\text { and essay } \\
\text { question }\end{array}$ & 6 years and above & 70 & 2.83 & 0.466 & -1.450 & 98 & .151 & NS \\
\hline \multirow[t]{2}{*}{ oral test } & Below 5 years & 30 & 1.83 & 0.699 & & & & \\
\hline & 6 years and above & 70 & 1.91 & 0.608 & -0.583 & 98 & .561 & NS \\
\hline \multirow[t]{2}{*}{ Practical work } & Below 5 years & 30 & 1.17 & 0.379 & & & & \\
\hline & 6 years and above & 70 & 1.16 & 0.439 & 0.903 & 98 & .918 & NS \\
\hline Submitted & Below 5 years & 30 & 1.40 & 0.724 & & & & \\
\hline homework & 6 years and above & 70 & 1.33 & 0.631 & 0.496 & 98 & .621 & NS \\
\hline \multirow[t]{2}{*}{ Students note } & Below 5 years & 30 & 1.53 & 0.730 & & & & \\
\hline & 6 years and above & 70 & 1.84 & 0.845 & -1.750 & 98 & .084 & NS \\
\hline
\end{tabular}

Table 2a shows the result of Yoruba language teachers' utilization of evaluation instrument by teaching experience. As presented in the table, only the use of multiple choice test was significant between teachers with six 
years and above teaching experience at $(\mathrm{t}=2.030, \mathrm{p}<0.05)$. All the other types of evaluation instruments were not significant.

Table 2b: Teachers' Utilization of Evaluation Instrument by Professional Status

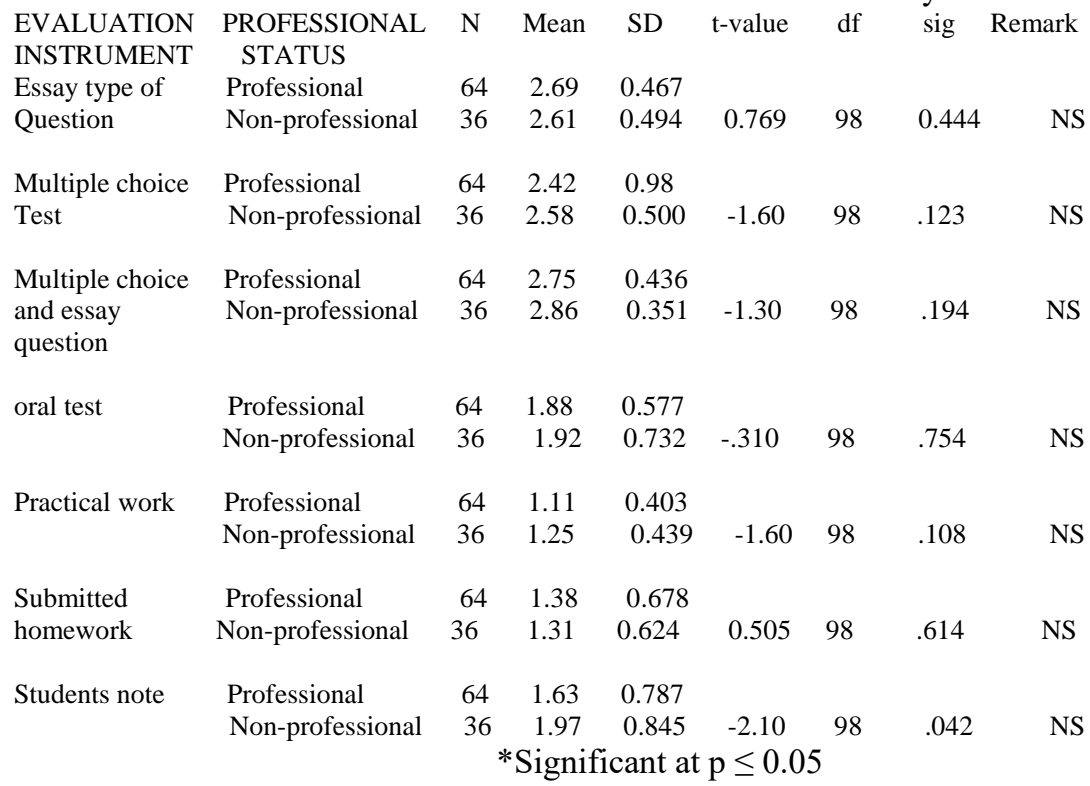

Table 2b which presents the Yoruba language teachers' utilization of evaluation instruments in terms of professional status shows that only the use of students note was significant between teachers with professional status (professional qualified) and those who do not have the qualification. The utilization of other evaluation instruments among those teachers was not significant.

Table 2c: Teachers' Utilization of Evaluation Instrument by Gender

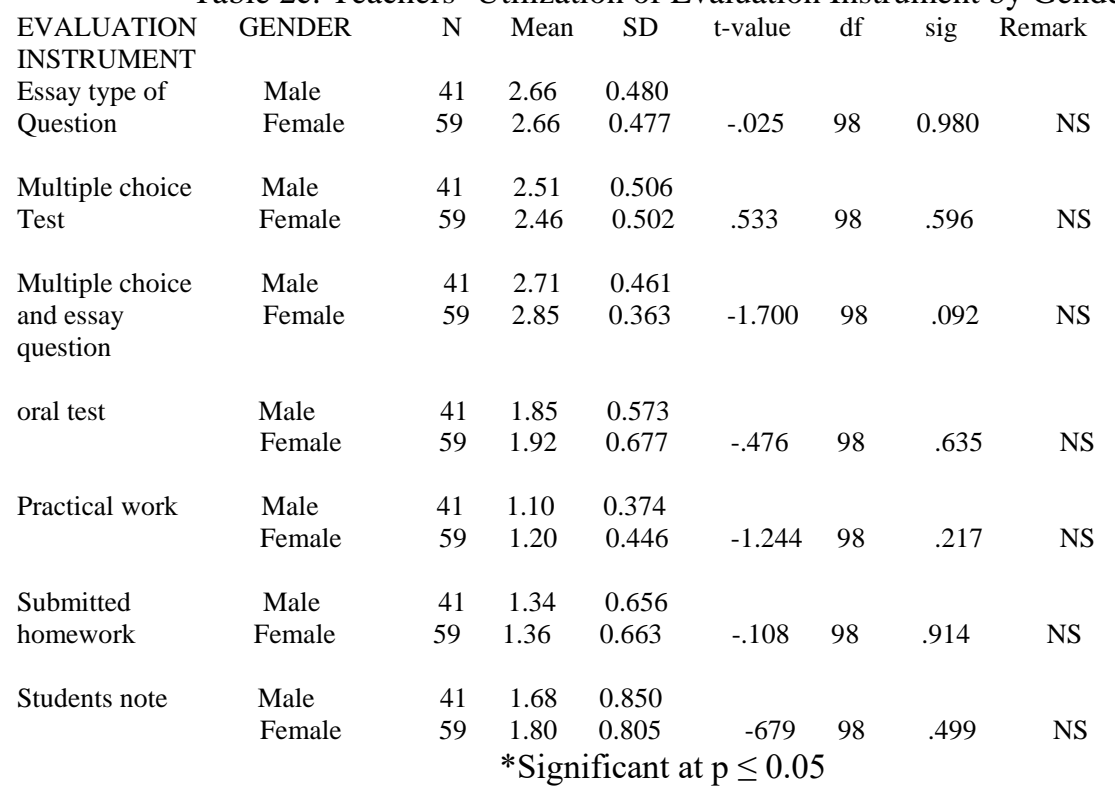


Table 2c presents the result of Yoruba language teachers' utilization of evaluation instruments by gender. The table reveals that the way the male and female Yoruba language teachers utilize the evaluation instruments were not statistically significant.

\section{Discussion}

The findings of this study is that Yoruba language teachers in Nigeria Secondary Schools tend to use multiple choice test, essay type of questions and combination of the essay and multiple choice types of questions more frequently. Though these teachers sometimes use oral tests and students notes, they hardly use practical work and submitted home work. The study findings also indicate that Yoruba language teacher's utilization of multiple choice test and students note were sensitive to teachers teaching experience and personal status, and nothing sensitive to teachers' gender. These findings imply that older experienced teachers of 6 years and above of teaching with a higher mean score of $\breve{x}=2.41$ and SD $=0.496$ utilize multiple choice test more frequently than teachers with between $1-5$ years of teaching with higher mean score of $\breve{x}=2.63$ and SD $=0.490$.

Teachers with professional training in pedagogy also utilize essay test and the essay test more often than those without professional training in evaluating students' work. In terms of gender, there is no statistical significant different in the use of evaluation instruments between male and female Yoruba Language teachers. These findings tend to disagree with test construction experts views that essay test are less difficult to construct than multiple choice test (Obemeata, 2000). According to him, identification of plausible distracters in multiple choice test construction is not a mean activity for untrained evaluators. The fact that the use of practical class work and submitted home work are not very popular among Yoruba Language teachers are indicators of over reliance of Yoruba teachers on pencil and paper tests. There are evaluation practices which tend to encourage the development of memorization and regurgitation of learnt materials in students.

It also goes to show that Yoruba language teachers are deficient in the use of alternative evaluation in students such as practical class where students will be fully involved in the teaching/learning process and desist from learning in abstract. In the practical class, average Yoruba students will see things themselves most especially those ancient things which we remain permanently within. Also, the use of take home assignment will help students to develop an independent study habit and deduce faults for themselves. These findings support the works of Odinko and Osokoya (2004), Okunleye and Falaye (2005) and Utoh (2006) who reported that 
school teachers indicated as their areas of need the construction and utilization of evaluation instruments in grading students.

\section{Conclusion and recommendations}

The observation in this study is that multiple choice test and a combination of multiple choice test and essay test are popular methods of grading Yoruba Language students in our school system. It is an indication that the traditional method of grading still pervades our school system. This situation portend serious dangers for the educational system if in the modern day teacher still encourage regurgitation of learnt facts and its attendant poor studying approach by students. Better attentive instrument of evaluating students such as the use of practical class whereby students will be exposing to language laboratory and student practicalize things themselves and visit Yoruba traditional homes (Ile Isenbaye Yoruba) where all ancient things will be made known to the students. Students will see real objects rather than learning in abstracts. Also, it is recommended that more emphasis should be placed on the use of take home assignment by Yoruba teachers. It makes students more involving and from an independent study habit.

\section{References:}

6. Abijo, J.A( 2009). Effects of Two Methods of Teaching Essay Writing on Student Learning Outcomes in Yoruba Language. Unpublished Ph.D Thesis, University of Ibadan.

7. Ajala, J.A (2005). Evaluation in Students classroom performance. In A.E Emeke, C.V. Abe (Eds) Evaluation in Theory and Practice (Pp 12 - 27).

8. Isiugo-Abanihe. I (2006). School Evaluation Concept Nature and role. Paper presented at a training workshop on Continuous assessment for teachers of staff school, university of Ibadan, Nigeria.

9. Obemeata, J.O (2000). Principles of essay and Multiple choice test construction. Ibadan Sterling- Horden Publishers (Nig) Ltd.

10. Obemeata, J.O (2003). The Neglected aspect of the quality of education in Nigeria. A valedictory lecture delivered at the Faculty of Education. Pen Services.

11. Odinko, M.N \& Osokoya, M.M (2002). A Survey of Instructional Needs of Primary School Teachers in Nigeria. West African Journal of Education XXIV (I), 11-21.

12. Okpala P.N, Onocha, C.O \& Oyedeji (1993). Measurement and Evaluation in Education. Ibadan Stirling - Horden Publishers (Nig) Ltd.

13. Okwilagwe, E.A. (2011). Assessment of Geography teachers Utilization of Evaluation Instruments in Grading Students: West African Journal of Education XXXI 1-9. 
14. Onibokun, O.M (1999). Evaluation of Social Studies in J.O. Obemeata, S.O. Ayodele \& M.A Araromi (Eds) Evaluation in Africa. Book in honour of Prof. E.A Yoloye (Pp 40-59) Ibadan, Nigeria Stirling-Horden Publishers (Nig) Ltd. 